\title{
STUDY OF BODY WEIGHT AND HEIGHT OF ADOLESCENTS FROM DIFFERENT ETHNIC GROUPS IN THE PLOVDIV REGION
}

\author{
Elena Merdzhanova ${ }^{1}$, Penka Angelova ${ }^{2}$, Nikolay Boyadjiev ${ }^{2}$, Valentina Lalova ${ }^{1}$, \\ Ralitsa Raycheva ${ }^{3}$, Gergana Petrova ${ }^{1}$ \\ 1) Department of Nursing Care, Faculty of Public Health, Medical University \\ of Plovdiv, Bulgaria. \\ 2) Department of Physiology, Faculty of Medicine, Medical University of \\ Plovdiv, Bulgaria. \\ 3) Department of Social Medicine and Public Health, Faculty of Public Health, \\ Medical University of Plovdiv, Bulgaria.
}

\begin{abstract}
:
Purpose: To study the body weight and height of adolescents and to compare them with gender and age standards. All the children are from the Plovdiv region.

Material and methods: About 185 children from three different ethnic groups have been studied. It also hase been developed and used specifically for this purpose an author's questionnaire for students, which contains open, closed, and mixed questions. Have been used descriptive statistics for quantitative (mean $\pm \mathrm{SD}$ ) and qualitative (percentage \pm SEp) variables, also T-test for proving statistically significant differences between two independent samples. A p-value $<0.05$ had been considered statistically significant for all tests. For the statistical processing, we have used the data analysis software IBM SPSS Statistics v. 25.

Results: The study was conducted in the Plovdiv district in the period of May 2019 - July 2019. The subject of the study has been 185 adolescents from different ethnic groups. The logical units of the study were schools in Plovdiv and the village of Karadzhovo, which is part of the Plovdiv municipality. The gender distribution is $101(56.6 \%)$ boys and $84(45.4 \%)$ girls. The study covered mainly 96 Bulgarian children $(51.89 \% \pm 3.67)$, followed by 30 Turkish $(16.22 \% \pm 2.71)$ and 59 Roma origin $(31.89 \%$ \pm 3.43 ). The group of adolescents has been included students aged $11-15$ years old. In the group of 11-year-olds, 61 (32.97\%) Bulgarian children usually play sports out of school, followed by 29 (15.67\%) Roma and 16 (8.65\%) Turkish children. We have proved statistically significant differences between mean weight, measured in our sample compared to the population standard for the age of 11 years old boys $(n=28,45.84 \pm 13.42 \mathrm{~kg}$ vs $n=134,39.74 \pm 7.15$ $\mathrm{kg}$; t-test $=2.34, \mathrm{p}=0.026)$ and girls $(\mathrm{n}=35,45.49 \pm 10.46 \mathrm{~kg}$ vs $\mathrm{n}=135,41.60 \pm 9.03 \mathrm{~kg}$; t-test=2.24, $\mathrm{p}=0.029)$, respectively. The height measured for both genders in this age group had not been statistically significantly different compared to the standard. No other differences between sample point estimates and population standard had been obtained by age groups and gender.

Conclusion: For the age of 11-12 years old children, higher body weight had been found in the Bulgarian boys. The girls with the average highest values had been of Turkish origin.
\end{abstract} ethnicities.

Keywords: adolescents, height, body weight, gender,
Human physical development is a complex and compound concept. It is a set of morphological and functional features of the organism, characterizing those aspects of the shape and structure of the human body, which determine certain physical and motor qualities, which are related to physical capacity and human health. Physical development can be seen as a dynamically changing state from birth to death. It is a complex of morpho-functional traits for the level of biological development, determined genetically and by environmental factors [1].

Little is known about physical activity, sedentary lifestyles, and different behaviors of adolescents related to health risks $[2,3]$. Physical development is a vital bio-social process that is characterized by rapid growth and development of all parts of the body, organs, and systems for the age of $0-15$ years [4]. Growth is a complex dynamic process [5]. Physical culture and sports are preventive means to maintain and strengthen human health. Life experience shows that they help to comprehensively solve the problems related to improving the health status of the population [6].

During growth, the morphofunctional unity of the organism is the basis for the regular interconnected and interdependent processes of growth, development, physical and functional maturation. During growth, anthropometric data are the main source for assessing the correspondence between them and the current standards for healthy physical development at different ages [7].

In recent years, not only in Bulgaria but also in $\mathrm{Eu}-$ rope and in the world in general, there has been an increase of interest in ethnic communities and in particular in their number, demographic development, spatial mobility, and territorial location. In our country, this interest can be said to be the greatest in relation to the Roma ethnic group. There are large discrepancies between the number of Romas reported in the official censuses and scientific, empirical research in this direction. Although the Roma ethnic group in Bulgaria is the second largest after the Turkish, there have been very few studies among this ethnic group [8]. 


\section{PURPOSE:}

To study the body weight and height of adolescents and to compare them with gender and age standards. All the children are from the Plovdiv region.

\section{MATERIAL AND METHODS:}

About 185 children from three different ethnic groups have been studied. Also have been developed and used specifically for this purpose as an author's questionnaire for students, which contains open, closed, and mixed questions. Have been used descriptive statistics for quantitative (mean $\pm \mathrm{SD}$ ) and qualitative (persentage \pm SEp) variables, also a T-test for proving statistically significant differences between two independent samples. A p-value/ $<$ / 0.05 had been considered statistically significant for all tests. For the statistical processing, we have used the data analysis software IBM SPSS Statistics v. 25

\section{RESULTS:}

The study was conducted in the Plovdiv district in the period of May 2019 - July 2019. The subject of the study has been 185 adolescents from different ethnic groups. The logical units of the study were schools in Plovdiv and the village of Karadzhovo, which is part of the Plovdiv municipality. The gender distribution is 101 (56.6\%) boys and $84(45.4 \%)$ girls. The study covered mainly 96 Bulgarian children $(51.89 \% \pm 3.67)$, followed by 30 Turkish $(16.22 \% \pm 2.71)$ and 59 Roma origin $(31.89 \% \pm 3.43)$ (fig. 1$)$.

Fig. 1. Distribution of respondents by ethnicity

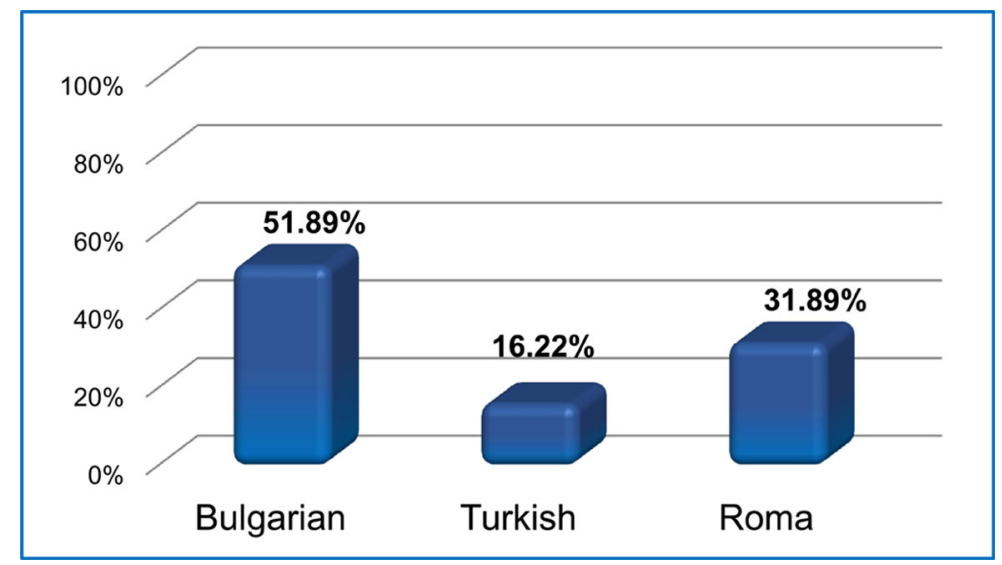

The group of adolescents has been included students aged 11 - 15 years old. At the time of the measurements, there had been children who were 15 years old. In the group of 11-year-olds, 61 (32.97\%) Bulgarian children usually play sports out of school, followed by 29 (15.67\%) Roma and 16 (8.65\%) Turkish children.

Anthropometry is a method of studying physical development by measuring the human body. An obligatory condition for the correctness of anthropometric measurements is that they are performed according to a certain standardized methodology and with accurate and correct equipment $[1,9]$

\section{Height}

Height is the main and most important evaluative anthropometric indicator for a person's physical development throughout his life. Its importance is greatest during growth because by correlating the dimensions of the other main anthropometric features to its dimensions, it is determined to what extent the respective harmonious body's proportionality and commensurability have been achieved during the different ages.

Measurement of height is in centimeters. It has been performed with a standard height meter or anthropometer with an accuracy of 0.5 centimeters.

Tables 1 and 2 show the mean values of the indicator and the standard deviation by age, sex and ethnicity obtained from the present study.

Table 1. Mean values for the indicator "Height" obtained from the present study in boys represented by age and ethnicity

\begin{tabular}{|c|c|c|c|c|c|c|c|}
\hline \multicolumn{9}{|c|}{ Boys - Bulgarian } \\
\hline Age & $\mathrm{n}$ & mean & $\min$ & $\max$ & SEM & SD & V \\
\hline 11 & 13 & 151.77 & 140 & 164 & 2.268 & 8.177 & 66.859 \\
\hline 12 & 20 & 155.05 & 140 & 175 & 2.149 & 9.611 & 92.366 \\
\hline 13 & 7 & 165.71 & 150 & 172 & 2.809 & 7.432 & 55.238 \\
\hline 14 & 12 & 169.25 & 152 & 186 & 2.926 & 10.137 & 102.750 \\
\hline
\end{tabular}




\begin{tabular}{|c|c|c|c|c|c|c|c|}
\hline \multicolumn{7}{|c|}{ Boys - Turkish } \\
\hline Age & $\mathrm{n}$ & mean & min & max & SEM & SD & V \\
\hline 11 & 3 & 149.33 & 145 & 155 & 2.963 & 5.132 & 26.333 \\
\hline 12 & 9 & 147.89 & 128 & 165 & 4.414 & 13.242 & 175.361 \\
\hline 13 & 3 & 150.33 & 138 & 165 & 7.881 & 13.650 & 186.333 \\
\hline 14 & 1 & 150.00 & 150 & 150 & & & \\
\hline \multicolumn{7}{|c|}{ Boys - Roma } \\
\hline Age & $\mathrm{n}$ & mean & min & max & SEM & SD & V \\
\hline 11 & 12 & 143.67 & 128 & 160 & 3.232 & 11.195 & 125.333 \\
\hline 12 & 9 & 148.33 & 136 & 175 & 4.549 & 13.647 & 186.250 \\
\hline 13 & 5 & 165.80 & 160 & 172 & 2.131 & 4.764 & 22.700 \\
\hline 14 & 2 & 161.50 & 150 & 173 & 11.500 & 16.263 & 264.500 \\
\hline 15 & 4 & 164.25 & 150 & 175 & 5.452 & 10.905 & 118.917 \\
\hline
\end{tabular}
ethnicity

Table 2. Mean values for the indicator " Height" obtained from the present study in girls represented by age and

\begin{tabular}{|c|c|c|c|c|c|c|c|}
\hline \multicolumn{8}{|c|}{ Girls - Bulgarian } \\
\hline Age & $\mathrm{n}$ & mean & $\min$ & $\max$ & SEM & $\mathrm{SD}$ & $\mathrm{V}$ \\
\hline 11 & 18 & 150.28 & 140 & 174 & 1.975 & 8.379 & 70.212 \\
\hline 12 & 12 & 155.00 & 138 & 165 & 2.594 & 8.985 & 80.727 \\
\hline 13 & 8 & 164.75 & 159 & 170 & 1.346 & 3.808 & 14.500 \\
\hline 14 & 1 & 160.00 & 160 & 160 & & & \\
\hline 15 & 5 & 165.60 & 158 & 170 & 2.064 & 4.615 & 21.300 \\
\hline \multicolumn{8}{|c|}{ Girls - Turkish } \\
\hline Age & $\mathrm{n}$ & mean & $\min$ & $\max$ & SEM & SD & $\mathrm{V}$ \\
\hline 11 & 9 & 147.11 & 128 & 166 & 4.012 & 12.036 & 144.861 \\
\hline 12 & 3 & 144.00 & 140 & 150 & 3.055 & 5.292 & 28.000 \\
\hline 13 & 1 & 166.00 & 166 & 166 & & & \\
\hline 14 & 1 & 145.00 & 145 & 145 & & & \\
\hline \multicolumn{8}{|c|}{ Girls - Roma } \\
\hline Age & $\mathrm{n}$ & mean & $\min$ & $\max$ & SEM & SD & V \\
\hline 11 & 8 & 145.25 & 139 & 165 & 2.914 & 8.242 & 67.929 \\
\hline 12 & 10 & 151.00 & 135 & 160 & 2.753 & 8.705 & 75.778 \\
\hline 13 & 5 & 151.40 & 140 & 170 & 6.112 & 13.667 & 186.800 \\
\hline 14 & 3 & 152.00 & 145 & 164 & 6.028 & 10.440 & 109.000 \\
\hline
\end{tabular}

\section{Body weight}

After growth, body weight is the second main characteristic for determining the specifics of a person's physical development during growth. Body weight data are the basis on which they have been determined anthropometrically: body composition; the type of bodily nutritional status and deviations from the norms for it; somato- type, which is a generalizing characteristic of physical development, etc. In (Tables 3 and 4 ) are reflected the data obtained from the measurement of body weight by age, sex and ethnicity.

Measurement of body weight is in kilograms. It is made with a calibrated electronic scale with an accuracy of 50 grams. 
Table 3. Mean values for the indicator "Body weight" obtained from the present study in boys represented by age and ethnicity

\begin{tabular}{|c|c|c|c|c|c|c|c|}
\hline \multicolumn{8}{|c|}{ Boys - Bulgarian } \\
\hline Age & $\mathrm{n}$ & mean & $\min$ & $\max$ & SEM & $\mathrm{SD}$ & $\mathrm{V}$ \\
\hline 11 & 13 & 49.308 & 33.0 & 79.0 & 3.9813 & 14.3549 & 206.064 \\
\hline 12 & 20 & 47.850 & 29.0 & 70.0 & 2.3734 & 10.6142 & 112.661 \\
\hline 13 & 7 & 56.000 & 34.0 & 76.0 & 5.8105 & 15.3731 & 236.333 \\
\hline 14 & 12 & 59.417 & 42.0 & 85.0 & 3.2414 & 11.2287 & 126.083 \\
\hline \multicolumn{8}{|c|}{ Boys - Turkish } \\
\hline Age & $\mathrm{n}$ & mean & $\min$ & $\max$ & SEM & SD & V \\
\hline 11 & 3 & 42.333 & 27.0 & 68.0 & 12.9142 & 22.3681 & 500.333 \\
\hline 12 & 9 & 43.944 & 32.0 & 60.0 & 3.6747 & 11.0240 & 121.528 \\
\hline 13 & 3 & 40.500 & 29.0 & 54.0 & 7.2858 & 12.6194 & 159.250 \\
\hline 14 & 1 & 41.000 & 41.0 & 41.0 & & & \\
\hline \multicolumn{8}{|c|}{ Boys - Roma } \\
\hline Age & $\mathrm{n}$ & mean & $\min$ & $\max$ & SEM & SD & V \\
\hline 11 & 12 & 42.958 & 28.5 & 60.0 & 2.8792 & 9.9737 & 99.475 \\
\hline 12 & 9 & 46.722 & 32.0 & 80.0 & 4.8384 & 14.5153 & 210.694 \\
\hline 13 & 5 & 56.500 & 50.0 & 66.5 & 3.1544 & 7.0534 & 49.750 \\
\hline 14 & 2 & 45.750 & 37.5 & 54.0 & 8.2500 & 11.6673 & 136.125 \\
\hline 15 & 4 & 64.625 & 50.0 & 92.5 & 9.5162 & 19.0323 & 362.229 \\
\hline
\end{tabular}

Table 4. Mean values for the indicator "Body weight" obtained from the present study in girls represented by age and ethnicity

\begin{tabular}{|c|c|c|c|c|c|c|c|}
\hline \multicolumn{8}{|c|}{ Girls - Bulgarian } \\
\hline Age & $\mathrm{n}$ & mean & $\min$ & $\max$ & SEM & $\mathrm{SD}$ & $\mathrm{V}$ \\
\hline 11 & 18 & 42.444 & 30.0 & 61.0 & 2.0883 & 8.8598 & 78.497 \\
\hline 12 & 12 & 49.750 & 38.0 & 71.0 & 2.6547 & 9.1961 & 84.568 \\
\hline 13 & 8 & 55.000 & 47.0 & 66.0 & 2.2599 & 6.3920 & 40.857 \\
\hline 14 & 1 & 56.000 & 56.0 & 56.0 & & & \\
\hline 15 & 5 & 53.600 & 45.0 & 58.0 & 2.2935 & 5.1284 & 26.300 \\
\hline \multicolumn{8}{|c|}{ Girls - Turkish } \\
\hline Age & $\mathrm{n}$ & mean & $\min$ & $\max$ & SEM & $\mathrm{SD}$ & $\mathrm{V}$ \\
\hline 11 & 9 & 49.556 & 32.0 & 76.0 & 4.1936 & 12.5808 & 158.278 \\
\hline 12 & 3 & 48.667 & 48.0 & 49.0 & 0.3333 & 0.5774 & 0.333 \\
\hline 13 & 1 & 78.000 & 78.0 & 78.0 & & & \\
\hline 14 & 1 & 46.000 & 46.0 & 46.0 & & & \\
\hline \multicolumn{8}{|c|}{ Girls - Roma } \\
\hline Age & $\mathrm{n}$ & mean & $\min$ & $\max$ & SEM & SD & $\mathrm{V}$ \\
\hline 11 & 8 & 47.750 & 39.0 & 72.0 & 3.6972 & 10.4574 & 109.357 \\
\hline 12 & 10 & 48.650 & 37.0 & 63.0 & 2.4072 & 7.6123 & 57.947 \\
\hline 13 & 5 & 58.100 & 37.0 & 116.0 & 14.8496 & 33.2047 & 1102.550 \\
\hline 14 & 3 & 44.500 & 37.5 & 50.0 & 3.6856 & 6.3836 & 40.750 \\
\hline
\end{tabular}


The Bulgarian boys (mean 49,308) have the largest body weight among the 11-year-olds, and the girls are of Turkish origin (mean 49,556). Among the 12-year-olds with the average highest values are again the Bulgarian children, as for the boys it is (mean 47,850), and for the girls (mean 49,750). For 13-year-old boys, Bulgarians (mean 56,000) and Roma (mean 56,500) have approximately the same average values. The 13-year-old girls with the highest body weight are Roma (mean 58,100).

After measuring the indicators of height and body weight, the BMI of the respondents was calculated. To calculate the Body mass index (BMI) is used recommended by the World Health Organization: $\mathrm{BMI}=$ weight $(\mathrm{kg}) /$ height $(\mathrm{m}) 2$. The index is calculated after results obtained from height and body weight $[9,10,11,12]$.

\section{Body Mass Index (BMI)}

Until recently, a unified, generally accepted by experts indicator for assessing the body's nutritional status in epidemiological studies during childhood and adolescence has not yet been found. Different formulas were introduced and used to determine the ideal weight, weightfor-height, weight-for-age, and so on. The information ca- pabilities of all these indicators were far from the requirements for an objective and comparable comparative assessment of the epidemiology of underweight and overweight during growth, including weight loss and obesity. No approach has been established and unified for setting the limit values for the categorization of bodily nutritional status. Different researchers had been used different mathematical approaches, such as: percentile method, Z - score, standard deviation (SD) method, etc. At the present stage of the development of biomedical science, this problem had found a satisfactory solution in grown individuals. The Body Mass Index (BMI) was introduced as an evaluation criterion for determining body nutritional status in adulthood. This index is a kind of integral characteristic that gives information about the amount of body weight distributed per unit of height [7].

Experts from the International Obesity Task Force (IOTF) and the WHO, respectively, believe that BMI is an internationally accepted criterion for assessing the nutritional status of adolescents [7, 13].

Tables 5 and 6 present the obtained average values for BMI distributed by age, sex and ethnicity.

Table 5. Mean values for the "BMI" indicator obtained from the present study in boys represented by age and ethnicity

\begin{tabular}{|c|c|c|c|c|c|c|c|}
\hline \multicolumn{8}{|c|}{ Boys - Bulgarian } \\
\hline Age & $\mathrm{n}$ & mean & $\min$ & $\max$ & SEM & SD & V \\
\hline 11 & 13 & 21.1929 & 16.01 & 29.37 & 1.34505 & 4.84966 & 23.519 \\
\hline 12 & 20 & 19.7142 & 14.80 & 26.56 & 0.66139 & 2.95783 & 8.749 \\
\hline 13 & 7 & 20.1697 & 14.19 & 25.69 & 1.68574 & 4.46006 & 19.892 \\
\hline 14 & 12 & 20.8164 & 14.53 & 29.41 & 1.17375 & 4.06599 & 16.532 \\
\hline \multicolumn{8}{|c|}{ Boys - Turkish } \\
\hline Age & $\mathrm{n}$ & mean & $\min$ & $\max$ & SEM & SD & $\mathrm{V}$ \\
\hline 11 & 3 & 18.5850 & 12.84 & 28.30 & 4.88615 & 8.46306 & 71.623 \\
\hline 12 & 9 & 20.0237 & 16.44 & 30.61 & 1.43785 & 4.31354 & 18.607 \\
\hline 13 & 3 & 17.5464 & 15.23 & 19.83 & 1.32996 & 2.30356 & 5.306 \\
\hline 14 & 1 & 18.2222 & 18.22 & 18.22 & & & \\
\hline \multicolumn{8}{|c|}{ Boys - Roma } \\
\hline Age & $\mathrm{n}$ & mean & $\min$ & $\max$ & SEM & SD & $\mathrm{V}$ \\
\hline 11 & 12 & 20.7644 & 12.67 & 28.54 & 1.15387 & 3.99713 & 15.977 \\
\hline 12 & 9 & 21.4740 & 16.33 & 40.82 & 2.52579 & 7.57736 & 57.416 \\
\hline 13 & 5 & 20.7056 & 16.90 & 25.98 & 1.67648 & 3.74872 & 14.053 \\
\hline 14 & 2 & 17.3547 & 16.67 & 18.04 & 0.68802 & 0.97300 & 0.947 \\
\hline 15 & 4 & 23.8443 & 18.29 & 32.01 & 2.90289 & 5.80579 & 33.707 \\
\hline
\end{tabular}

Table 6. Mean values for the "BMI" indicator obtained from the present study for girls represented by age and ethnicity

\begin{tabular}{|c|c|c|c|c|c|c|c|}
\hline \multicolumn{9}{|c|}{ Girls - Bulgarian } \\
\hline Age & $\mathrm{n}$ & mean & $\min$ & $\max$ & SEM & SD & V \\
\hline 11 & 18 & 18.6994 & 14.67 & 25.10 & 0.71783 & 3.04552 & 9.275 \\
\hline 12 & 12 & 20.7615 & 15.82 & 28.08 & 1.06141 & 3.67682 & 13.519 \\
\hline
\end{tabular}




\begin{tabular}{|c|c|c|c|c|c|c|c|}
\hline 13 & 8 & 20.2748 & 17.69 & 25.15 & 0.85480 & 2.41774 & 5.845 \\
\hline 14 & 1 & 21.8750 & 21.88 & 21.88 & & & \\
\hline 15 & 5 & 19.5019 & 18.03 & 20.57 & 0.44737 & 1.00035 & 1.001 \\
\hline \multicolumn{7}{|c|}{ Girls - Turkish } \\
\hline Age & $\mathrm{n}$ & mean & min & $\max$ & SEM & SD & V \\
\hline 11 & 9 & 23.0184 & 17.63 & 36.15 & 2.02221 & 6.06663 & 36.804 \\
\hline 12 & 3 & 23.5228 & 21.78 & 24.49 & 0.87420 & 1.51416 & 2.293 \\
\hline 13 & 1 & 28.3060 & 28.31 & 28.31 & & & \\
\hline 14 & 1 & 21.8787 & 21.88 & 21.88 & & & \\
\hline \multicolumn{7}{|c|}{ Girls - Roma } \\
\hline Age & $\mathrm{n}$ & mean & min & max & SEM & SD & V \\
\hline 11 & 8 & 22.4158 & 19.07 & 26.45 & 0.87856 & 2.48494 & 6.175 \\
\hline 12 & 10 & 21.4541 & 15.60 & 27.04 & 1.14470 & 3.61985 & 13.103 \\
\hline 13 & 5 & 24.0958 & 18.88 & 40.14 & 4.03594 & 9.02463 & 81.444 \\
\hline 14 & 3 & 19.2742 & 17.35 & 21.88 & 1.35025 & 2.33871 & 5.470 \\
\hline
\end{tabular}

Comparison of the obtained average values of the indicators (height, body weight and BMI) with the standard averages compared by sex and age.

The data obtained from the study of adolescents for body weight, height and BMI are compared with the latest transversal and most recent study of BAS (Bulgarian Academy of Science) on "Physical development of children and adolescents in Bulgaria at the turn between the XX and XXI century" (2012). The authors do not claim that these standards are accepted as national standards, so they present them as "exemplary". Their relevance, against the background of the lack of updated national growth anthropological standards for more than 30 years, is an objective prerequisite for the growth anthropometric curves developed by them to be used in assessing the physical development of the current generation of Bulgarian children at birth and between 3 and 17 years [7].

We have been proved statistically significant differences between mean weight, measured in our sample compared to the population standard for the age of 11 years old boys $(\mathrm{n}=28,45.84 \pm 13.42 \mathrm{~kg}$ vs $\mathrm{n}=134,39.74 \pm$ $7.15 \mathrm{~kg}$; t-test $=2.34, \mathrm{p}=0.026)$ and girls $(\mathrm{n}=35,45.49 \pm$ $10.46 \mathrm{~kg}$ vs $\mathrm{n}=135,41.60 \pm 9.03 \mathrm{~kg}$; t-test $=2.24, \mathrm{p}=$ $0.029)$, respectively. The height measured for both genders in this age group was not a statistically significant difference compared to the standard. No other differences between sample point estimates and population standard had been obtained by age groups and gender.

The comparison of the BMI of the respondents with the used standards gave the following results.

We had been proved statistically significant differences between the average BMI scores of boys, measured in our sample and the standard population scores at age 11 yrs. $(t=2.73, p=0.011)$ and 12 yrs. $(t=2.33, p=0.027)$. Differences were observed between the average BMI scores of girls at the same age $-11 \mathrm{yrs} .(\mathrm{t}=2.98, \mathrm{p}=0.006)$ and $12 \mathrm{yrs}$. $(t=3.20, p=0.004)$. In our sample, the BMI average scores by gender and age are statistically significantly higher compared to the standard population scores (Table 7).

Table 7. Comparison of the obtained mean values for "BMI" with the average values of the standard

\begin{tabular}{|c|c|c|c|c|c|c|c|c|c|c|}
\hline \multirow{2}{*}{ gender } & \multirow{2}{*}{$\begin{array}{l}\text { age } \\
\text { (yrs.) }\end{array}$} & \multirow{2}{*}{ variable } & \multicolumn{3}{|c|}{ Sampe } & \multicolumn{3}{|c|}{ Population Standard } & \multirow{2}{*}{ t-test } & \multirow{2}{*}{ p-value } \\
\hline & & & $\mathrm{N}$ & Mean & SD & $\mathrm{N}$ & Mean & SD & & \\
\hline \multirow[t]{5}{*}{ boys } & 11 & \multirow{10}{*}{ BMI } & 28 & 20.73 & 4.78 & 134 & 18.19 & 2.66 & 2.73 & 0.011 \\
\hline & 12 & & 38 & 20.20 & 4.63 & 132 & 18.40 & 2.59 & 2.33 & 0.027 \\
\hline & 13 & & 15 & 19.82 & 3.84 & 136 & 19.55 & 3.27 & 0.26 & $\mathrm{p}>0.05$ \\
\hline & 14 & & 15 & 20.18 & 3.85 & 134 & 19.51 & 3.24 & 0.64 & $\mathrm{p}>0.05$ \\
\hline & 15 & & 4 & 23.94 & 5.81 & 135 & 20.04 & 3.34 & 1.16 & $\mathrm{p}>0.05$ \\
\hline \multirow[t]{5}{*}{ girls } & 11 & & 35 & 20.66 & 4.37 & 135 & 18.38 & 3.01 & 2.98 & 0.006 \\
\hline & 12 & & 25 & 21.37 & 3.47 & 135 & 19.05 & 3.38 & 3.20 & 0.004 \\
\hline & 13 & & 14 & 22.21 & 5.89 & 134 & 19.68 & 3.69 & 1.54 & $\mathrm{p}>0.05$ \\
\hline & 14 & & 5 & 20.32 & 2.18 & 136 & 19.33 & 2.98 & 0.90 & $\mathrm{p}>0.06$ \\
\hline & 15 & & 5 & 19.50 & 1.00 & 135 & 19.90 & 2.91 & 0.77 & $\mathrm{p}>0.07$ \\
\hline
\end{tabular}




\section{DISCUSSION:}

There are very few areas of scientific knowledge whose results have such great medical and biological significance as the results of anthropometric studies of the physical development of a country's population. The collection and analysis of anthropological data for different generations of the modern population of our country are of great importance for Bulgarian anthropological science. When evaluating these data, results are obtained, both of scientific and scientific-applied significance. It is especially important during growth to look for and detect any deviation from the norms of physical development for the respective age because it is the basis for the future complication to more serious deviations from these norms or even to diseases that can be successfully prevented by their early detection and the application of subsequent adequate prevention and treatment [14]. When children are 10-11 years old, they grow rapidly. Qualitative changes occur in the development of their organs and systems, limbs lengthen, body weight changes rapidly, and the ossification of cartilage tissues accelerates [15]. The process of obesity of students after 7 years of age increases, and by 12 years are the highest, around 14 years decreases, and by 16-17 years increases again [16]. The results obtained for height, weight and BMI can also be analyzed from the context of lifestyle, eating habits and the influence of the family over them. Adolescents are a specific group for studying eating behavior due to various factors that affect this period of their lives $[17 ; 18]$. A correlation has been established between the BMI of children and their parents [19]. The health culture and health literacy of adolescents should not be underestimated as factors influencing BMI [20]. According to Geserik M. et al. 1 and Ward Z., the dynamics of body-mass index (BMI) in children from birth to adolescence are unclear, and whether susceptibility for the development of sustained obesity occurs at a specific age in children is important to determine. Among obese adolescents, the most rapid weight gain had occurred between 2 and 6 years of age; most children who have been obese at that age were obese in adolescence. (Funded by the German Research Council for the Clinical Research Center "Obesity Mechanisms" and others; Clinical Trials. gov number, NCT03072537.) [21, 22].

\section{CONCLUSION:}

We found that for the age of 11-12 years with the highest average values are the Bulgarian boys, followed by Turks and Roma. For the ages of 13-15, the Bulgarian boys are again the tallest, followed by Roma and Turks. Among girls, in all studied age groups, the highest are the Bulgarian girls. From the obtained average values for the body weight, the highest averages are observed for the Bulgarian boys for the age of 11 - 14 years. Among girls for the age group 11-12 years, the most severe are the girls of Turkish origin, followed by Roma and Bulgarians, which correlates with the higher average values obtained for BMI by sex, age and ethnicity. The comparison of the obtained BMI averages with the averages of the standard confirms the trend for the age group $11-12$ years, which are significant with higher averages of BMI compared to the standards. From the comparison of the obtained average values with the average values of the adopted standard, a statistically significant difference has been found for the body weight indicator in the measured 11-year-old children of both sexes, which were significantly heavier. With equal growth with the population norm, statistically, a significant higher weight is associated with a risk of obesity in this age group.

\section{Acknowledgements:}

Gratitudes to the principals of the schools in which the measurements of the students and the management of MU - Plovdiv were performed for the support and trust for the implementation of the project.

\section{Conflicts of interest:}

There is no conflict of interest in the realization of this scientific work. The scientific work has been presented to the Scientific Ethics Committee on June 13 2019, which gave its opinion with an order of The Rector of Medical University - Plovdiv No. P-1742 / 28. 06. 2019. This scientific study has been conducted under the project NO-12/ 2019 of the Medical University of Plovdiv on the topic: Physical development and health behavior of adolescents (11-14 years old) from different ethnic groups in the Municipality of Plovdiv.

\section{REFERENCES:}

1. Topuzov I. [Sports medicine and hygiene] Blagoevgrad SWU Neofit Rilski 2007 [in Bulgarian].

2. Nelson MC, Gordon-Larsen P. Physical activity and sedentary behavior patterns are associated with selected adolescent health risk behaviors. Pediatrics. 2006 Apr; 117(4):1281-90. [PubMed]

3. Riddoch CJ, Bo AL, Wedderkopp N, Harro M, Klasson-Heggebo L, Sardinha LB, et al. Physical activity levels and patterns of 9- and 15-yr-old European children. Med Sci Sports Exerc. 2004; 36:86-92. [Crossref]

4. Kahn JA, Huang B, Gillman MW, Field AE, Austin SB, Colditz GA. et al. Patterns and Determinants of Physical Activity in U.S. Adolescents J Adolesc Health 2008 Apr;42(4):369-77. [PubMed]

5. Shmilev T. [Handbook for diagnosis and treatment of children's diseases]. Plovdiv, MI Raykov 2014. [In
Bulgarian].

6. Milanova P. Lifestyle and health status of adolescents. [Dissertation] Sofia NSA 2012. [in Bulgarian].

7. Nacheva A, Zhecheva Y, Yankova I, Filcheva Z, Mitova Z, Yordanov J. [Physical development of children and adolescents in Bulgaria between the XX and XXI century.] Sofia: Ed. of BAS Prof. Marin Drinov 2012. [In Bulgarian].

8. Ilieva N. [Number of the Roma 
Ethnic Group in Bulgaria from the Liberation (1878) to the beginning of the XXI Century According to the Reckoning. Part I.] [in Bulgarian] BAS. Problems of Geography. 2012; 3-4:61-79. [Internet].

9. Slanchev P. [Sports Medicine] Sofia, New Knowledge, 1998. [In Bulgarian].

10. Francisa LA, Grangerb DA, Susmana EJ. Adrenocortical regulation, eating in the absence of hunger and BMI in young children. Appetite. 2013 May;64(1):32-8. [PubMed]

11. Kantanista A, Osiñski W, Borowiec J, Tomczak M, Król-Zieliñska M. Body image, BMI, and physical activity in girls and boys aged 14-16 years. Body Image. 2015 Sep;15:40-3. [PubMed]

12. Klein D, De Toia D, Weber $S$, Wessely N, Koch B, Dordel S, at al. Effects of a low threshold health promotion intervention on the BMI in preschool children under consideration of parental participation. ESPEN J. 2010 Jun;5(3):e125-e131. [Crossref]

13. Lobstein T. Commentary: which child obesity definitions predict health risk? Ital J Pediatr. 2017 Feb 4; 43(1):20. [PubMed]

14. Temelkova-Kurktschiev T, Stefanov T. Lifestyle and genetics in obesity and type 2 diabetes. Exp Clin Endocrinol Diabetes. 2012; 120(1):1-6.

15. Peneva P. [The athletics lesson in nature - a factor for increasing the physical capacity of ten-year-old students.] Scientific works of the University of Ruse 2008; 47(9):245-9. [in Bulgarian]

16. Nikolova E, Marinov B. [Physical activity - school family.] Sofia; BOLID-INC: 2002. [in Bulgarian].

17. Taljic I, Hadzic A, Djukic Ratkovic D. Perception and satisfaction with body imageaccording to the nutritional status among adolescents boys from urban and rural areas of the Sarajevo Canton. In: 10th International Scientific and Professional Conference Proceedings: With Food to Health, Josip Juraj Strossmayer University of Osijek, Faculty of Food Technology Osijek and Faculty of Pharmacy, University of Tuzla, Osijek, Croatia 2017. pp. 9-14.

18. Taljic I, Toroman A. Category of nutritional status of adolescents accord- ing to gender andtype of settlement: results of Canton Sarajevo. Hrana $i$ ishrana (Beograd). 2016; 57(1):13-18.

19. Taljic I, Memisevic H. Impact of Parental BMI on Adolescents' BMI: Moderating Effects of Gender. In: 30th Scientific-Experts Conference of Agriculture and Food Industry. AgriConf 2019. IFMBE Proceedings, vol 78. Brka M, Omanovic-Miklicanin E, Karic L, Falan V, Toroman A. (eds). Springer, Cham. 04 February 2020. [Crossref]

20. Saedi F, Panahi R. The Survey of association between health literacy and BMI among adolescents. $J$ Health Literacy. 2017 Spring;2(1):22-30. [Crossref]

21. Geserik M, Vogel M, Gaushe R, Lipek T, Spielau U, Keller E, et al. Acceleration of BMI in Early Childhood and Risk of Sustained Obesity. $N$ Engl J Med. 2018 Oct 4;379(14):1303-1312. [PubMed]

22. Ward ZJ. 2-6 years-of-age is the period associated with greatest BMI acceleration among obese adolescents. $J$ Pediatr. 2019 Mar;206:298-301. [PubMed]

Please cite this article as: Merdzhanova E, Angelova P, Boyadjiev N, Lalova V, Raycheva R, Petrova G. Study of body weight and height of adolescents from different ethnic groups in the Plovdiv region. J of IMAB. 2021 Jul-Sep;27(3):38733880. DOI: https://doi.org/10.5272/jimab.2021273.3873

Received: 07/05/2021; Published online: 09/08/2021

\author{
Address for correspondence: \\ Assoc. Prof. Gergana Petrova, PhD \\ Department of Nursing Care, Faculty of Public Health, Medical University of \\ Plovdiv \\ 15 A, Vasil Aprilov Blvd., Plovdiv - 4002, Bulgaria. \\ E-mail: Gergana.Petrova@mu-plovdiv.bg
}

